\title{
A novel FRET peptide assay reveals efficient Helicobacter pylori HtrA inhibition through zinc and copper binding
}

Sabine Bernegger ${ }^{1}$, Cyrill Brunner ${ }^{2}$, Matej Vizovišek ${ }^{3}$, Marko Fonovic ${ }^{3}$, Gaetano Cuciniello ${ }^{1,8}$ Flavia Giordano ${ }^{4,9}$, Vesna Stanojlovic ${ }^{4}$, Miroslaw Jarzab ${ }^{1}$, Philip Simister ${ }^{5}$, Stephan M. Feller ${ }^{6}$, Gerhard Obermeyer ${ }^{7}$, Gernot Posselt ${ }^{1}$, Boris Turk ${ }^{3}$, Chiara Cabrele ${ }^{4}$, Gisbert Schneider ${ }^{2}$ \& Silja Wessler ${ }^{1 凶}$

Helicobacter pylori $(H$. pylori) secretes the chaperone and serine protease high temperature requirement $A(H \operatorname{trA})$ that cleaves gastric epithelial cell surface proteins to disrupt the epithelial integrity and barrier function. First inhibitory lead structures have demonstrated the essential role of HtrA in $\mathrm{H}$. pylori physiology and pathogenesis. Comprehensive drug discovery techniques allowing high-throughput screening are now required to develop effective compounds. Here, we designed a novel fluorescence resonance energy transfer (FRET) peptide derived from a gel-based label-free proteomic approach (direct in-gel profiling of protease specificity) as a valuable substrate for $H$. pylori HtrA. Since serine proteases are often sensitive to metal ions, we investigated the influence of different divalent ions on the activity of $\mathrm{HtrA}$. We identified $\mathrm{Zn}^{++}$and $\mathrm{Cu}^{++}$ions as inhibitors of $H$. pylori HtrA activity, as monitored by in vitro cleavage experiments using casein or E-cadherin as substrates and in the FRET peptide assay. Putative binding sites for $\mathrm{Zn}^{++}$and $\mathrm{Cu}^{++}$were then analyzed in thermal shift and microscale thermophoresis assays. The findings of this study will contribute to the development of novel metal ion-dependent protease inhibitors, which might help to fight bacterial infections.

Gastric cancer is associated with one of the highest mortality rates among all cancerous diseases in humans since efficient treatment options are still not available ${ }^{1}$. Persistent infections with the gastric pathogen Helicobacter pylori (H. pylori) are a significant risk factor for the induction and progression of stomach cancer. Approximately $50 \%$ of the human population is infected with $H$. pylori, which can induce chronic gastritis, duodenal, and gastric ulcers and finally gastric adenocarcinoma or MALT (mucosa-associated lymphoid tissue) lymphoma ${ }^{2,3}$. Accordingly, the complex network of cellular and molecular mechanisms of $H$. pylori-host interactions has been intensively investigated.

The finding that the serine protease high temperature requirement A (HtrA) expressed by $H$. pylori targets cell surface proteins of infected host cells added an important aspect to the model of $H$. pylori pathogenesis. During infection, $H$. pylori secretes HtrA and cleaves off the ectodomain of the cell adhesion protein and tumor

${ }^{1}$ Microbiology, Department of Biosciences, University of Salzburg, Billrothstrasse 11, 5020 Salzburg, Austria. ${ }^{2}$ Institut für Pharmazeutische Wissenschaften, ETH Zürich, Vladimir-Prelog-Weg 4, 8093 Zurich, Switzerland. ${ }^{3}$ Department of Biochemistry and Molecular and Structural Biology, Jozef Stefan Institute, Jamova 39, 1000 Ljubljana, Slovenia. ${ }^{4}$ Organic Chemistry and NMR Spectroscopy for Protein Research, Department of Biosciences, University of Salzburg, Billrothstrasse 11, 5020 Salzburg, Austria. ${ }^{5}$ Biological Systems Architecture Group, Department of Oncology, Weatherall Institute of Molecular Medicine, University of Oxford, Oxford, UK. ${ }^{6}$ Tumor Biology Unit, Institute of Molecular Medicine, Charles Tanford Protein Center, Martin-Luther-University Halle-Wittenberg, Halle, Germany. ${ }^{7}$ Membrane Physics, Department of Biosciences, University of Salzburg, Billrothstrasse 11, 5020 Salzburg, Austria. ${ }^{8}$ Present address: University of Milan, Via Festa del Perdono 7, 20122 Milan, Italy. ${ }^{9}$ Present address: Dipartimento Di Farmacia, Università Di Napoli "Federico II", Via D. Montesano, 49, 80131 Naples, Italy. ${ }^{\circledR}$ email: silja.wessler@sbg.ac.at 
suppressor E-cadherin, which was identified as the first HtrA substrate significant for pathogenesis ${ }^{4}$. E-cadherin is the key molecule of adherens junctions and necessary for establishing and maintaining intact intercellular adhesions between epithelial cells. Loss of E-cadherin function has drastic consequences not only on the epithelial architecture, but also on tumor prevention through the lack of recruitment of cancer-associated signal transduction molecules like $\beta$-catenin or p120-catenin ${ }^{5,6}$. In fact, E-cadherin ectodomain shedding leads to the disintegration of intercellular adhesion and promotes malignity of gastric, pancreatic, or breast cancer ${ }^{7,8}$. Therefore, E-cadherin cleavage serves as a reliable cancer biomarker ${ }^{9,10}$.

Structurally, E-cadherin is composed of an extracellular domain (EC), a transmembrane domain (TMD) and an intracellular domain (IC). The EC domain consists of the five tandem repeats EC1-EC5 with interspaced calcium-binding motifs, which are required for functional homophilic cis and trans interactions of E-cadherin between epithelial cells ${ }^{6}$. Importantly, these sites have been identified as preferred signature motifs for $H$. pylori $\mathrm{HtrA}^{11}$. Later studies indicated that the presence of calcium ions efficiently blocks E-cadherin cleavage by interfering with the accessibility of calcium-binding regions representing HtrA cleavage sites ${ }^{12}$. Additional HtrA substrates, including fibronectin, occludin, and claudin-8, have been described, confirming the capability of HtrA to break open intercellular adhesions and to disrupt the integrity of the epithelial barrier ${ }^{13}$. As a consequence, HtrA paves the intercellular way for $H$. pylori to transmigrate across the epithelial layer and to facilitate $\beta 1$-integrinmediated delivery of the bacterial oncoprotein cytotoxin-associated gene A $(\mathrm{CagA})^{4,13}$.

HtrA proteins are widely expressed and their role in bacterial pathogenesis is well established. The HtrA proteins of several pathogens have been suggested to process adhesins, as htrA deletion mutants of Streptococcus pneumoniae, Listeria monocytogenes, Staphylococcus aureus, etc. show a reduced ability to colonize host cells or tissues $^{14,15}$. Similar findings have been reported for Shigella flexneri DegP, which is important for the surface exposure of the virulence factor and autotransporter intra/intercellular spread protein A (IcsA) ${ }^{16}$. Chlamydia trachomatis secretes HtrA from chlamydial inclusions into the host cytoplasm, where it plays a critical role in the chlamydial developmental cycle ${ }^{17,18}$. However, HtrA-mediated E-cadherin cleavage appears to be a prevalent mechanism since similar observations have also been made for Campylobacter jejuni, enteropathogenic Escherichia coli (EPEC), Salmonella enterica subsp. enterica ser. Typhimurium, Yersinia enterocolitica, and Proteus mirabilis ${ }^{19-22}$

The structure and regulation of prokaryotic HtrA proteases have already been extensively studied in E. coli, which expresses the three homologues DegP, DegQ, and DegS ${ }^{23}$. DegP proteins in Gram-negative bacteria comprise of an $\mathrm{N}$-terminal signal peptide, followed by a chymotrypsin-like protease domain with the catalytic triad histidine, aspartic acid, and serine residues. Substrate recognition, binding, and HtrA/DegP homo-oligomerization are mainly mediated by the two C-terminally located PDZ (Post synaptic density of $95 \mathrm{kDa}$, Discs large, Zonula occludens-1) modules ${ }^{24}$. HtrA/DegP protease activity has been associated with the formation of higher order multimers composed of trimers. DegP is thought to form inactive hexameric oligomers that are converted into proteolytic active oligomers consisting of 12-24 HtrA monomers upon substrate binding ${ }^{25-27}$.

Computational drug design has identified functional HtrA inhibitors docking either into the active pocket of HtrA or interfering with an allosteric ligand-binding site that is important for HtrA oligomerization ${ }^{4,28,29}$. The development of a substrate-derived peptide inhibitor further emphasized the significance of HtrA activity in $H$. pylori pathogenesis ${ }^{11}$. Importantly, bacterial HtrA also functions as a chaperone that refolds and degrades misfolded proteins under stress conditions ${ }^{30}$. Due to this important function in bacterial physiology, HtrA expression is essential for $H$. pylori. This is obviously a unique phenotype for $H$. pylori $i^{31,32}$ as deletion of the $h t r A$ gene from the bacterial genome has not yet been reported to be lethal for other bacteria. The unexpected finding that small molecule inhibitors targeting HtrA can efficiently block $H$. pylori growth and survival ${ }^{31}$ indicates that $H$. pylori HtrA could be an attractive target for screening of pharmacological inhibitors.

In this study, we established a novel fluorescence assay based on Förster resonance energy transfer (FRET) that is suitable for high-throughput screenings and determining the effect of divalent ions on the activity of $\mathrm{HtrA}$. Previous studies have reported that $\mathrm{Zn}^{++}$can directly block the activity of serine proteases and potentiate moderate serine protease inhibitors by chelating the inhibitor to the histidine and serine of the catalytic triad in the active center ${ }^{33}$. In our study, we found that $\mathrm{Zn}^{++}$and $\mathrm{Cu}^{++}$can block HtrA activity and hence, we hypothesize that $\mathrm{Zn}^{++}$or $\mathrm{Cu}^{++}$could function as a co-inhibitor of HtrA proteases.

\section{Results and discussion}

A novel FRET peptide assay to determine the activity of $\boldsymbol{H}$. pylori HtrA. So far, the activity of $H$. pylori HtrA (HpHtrA) has been mainly investigated by casein zymography or Western blot analyses of substrate fragments, which are laborious, slow, and low-throughput methods $s^{28,34}$. FRET technology represents state-ofthe-art methodology and allows continuous assays of protease activity and high-throughput screening of protease inhibitors. To develop a FRET peptide assay containing an optimized short cleavage site for HtrA, we performed global specificity profiling for HtrA using a direct in-gel profiling of protease specificity (DIPPS) assay ${ }^{35}$. Analyzing HtrA-targeted proteome-derived peptides from MKN-28 cells, we detected 2,479 peptides that were processed by HtrA. These peptides were commonly cleaved after the aliphatic amino acid residues V, I and A in $\mathrm{P} 1$ position, while preference for basic amino acid residues such as $\mathrm{R}$ and $\mathrm{K}$ was observed in $\mathrm{P} 2$ position. Specificity of other non-prime binding sites was less pronounced, with R showing the highest enrichment at the P3 position and $\mathrm{A}$ at $\mathrm{P} 4$. Among the prime sites, the amino acids $\mathrm{A}$ and $\mathrm{K}$ were shown to be enriched at $\mathrm{P} 1^{\prime}$ position and $\mathrm{Y}$ at $\mathrm{P} 2^{\prime}$ position (Fig. $1 \mathrm{~A}$, left panel, Fig. S1). The detected characteristic specificity profile AR/QRV $\downarrow A Y$ corresponds well with the signature site [VITA] $\downarrow[$ VITA]- $x-x-D-[D N]$ previously identified in the HtrA substrate $\mathrm{E}$-cadherin and verifies the preference of HpHtrA to cleave between hydrophobic amino acids ${ }^{11}$. Interestingly, the sequence AR/QRV $\downarrow$ AY resembles the AQPVEA linker region between the EC5 and the TMD of E-cadherin that has already been suggested as a preferred cleavage site in E-cadherin for HpHtrA during the infection 

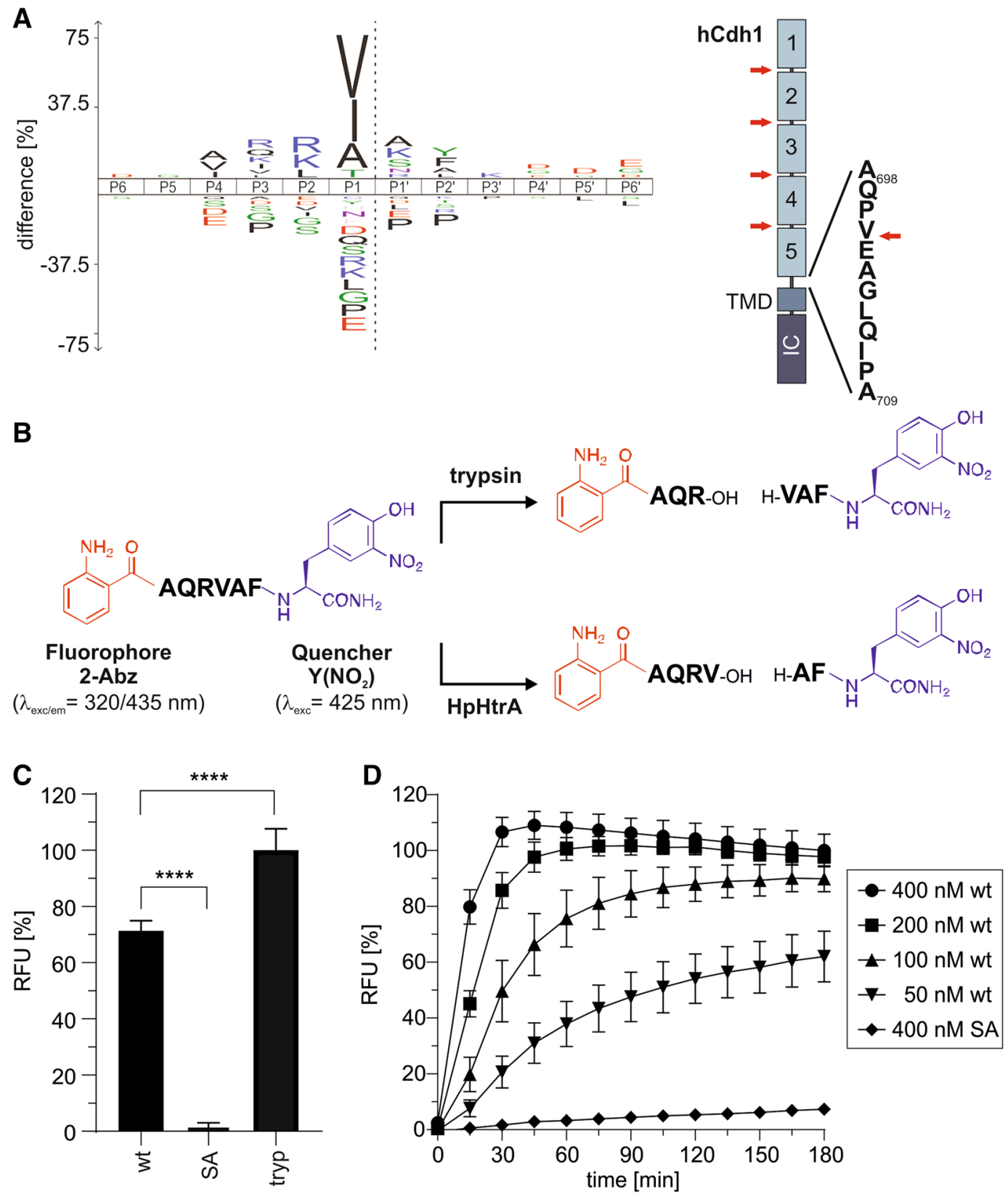

Figure 1. A novel FRET peptide assay to detect $H$. pylori HtrA activity. (A) The cleavage specificity profile of $\mathrm{HpHtrA}$ obtained from DIPPS profiling is represented as an iceLogo, with significantly enriched and underrepresented amino acids above and below the $x$-axis, respectively. The scissile peptide bond between P1 and P1' is shown as a gray dashed line in the iceLogo. The model on the right represents the domain structure of human E-cadherin (hCdh1), which is composed of the extracellular domain (EC1-EC5), a transmembrane domain (TMD) and an intracellular domain (IC). HtrA cleavage sites have been identified (red arrows) in the $\mathrm{Ca}^{++}$-binding sites located between the individual EC regions. According to the iceLogo, an additional cleavage site for HtrA is present in the linker region between the EC5 domain and TMD. (B) The sequence AQRVAF harboring 2-aminobenzoyl (2-Abz) as fluorophore and 3-nitro-tyrosine $\left.\mathrm{Y}_{2} \mathrm{NO}_{2}\right)$ as a quencher is hydrolyzed by trypsin with arginine (R) at position $\mathrm{P} 1$ and by HpHtrA with valine $(\mathrm{V})$ at position P1. (C) $5 \mu \mathrm{M}$ of the FRET peptide were incubated with $250 \mathrm{nM}$ of HpHtrA wild type (wt), its isogenic inactive mutant (SA), or $125 \mathrm{nM}$ trypsin for $180 \mathrm{~min}$ in $50 \mathrm{mM} \mathrm{HEPES}$ buffer $\left(\mathrm{pH} \mathrm{7.4)}\right.$ at $37^{\circ} \mathrm{C}$. The data represent the relative fluorescent units $(\mathrm{RFU}) \pm$ S.D. with the fluorescent signal obtained from trypsin-treated FRET peptide set as $100 \%$. Asterisks indicate statistically significant differences $\left({ }^{* * *} p<0.0001\right)$. (D) $4 \mu \mathrm{M}$ of the FRET peptide were incubated with indicated concentrations of HpHtrA wt or SA for $180 \mathrm{~min}$ at $37^{\circ} \mathrm{C}$ in $50 \mathrm{mM}$ HEPES buffer (pH 7.4). The data represent the RFU \pm S.D. with the fluorescent signals obtained from FRET peptide treated with $400 \mathrm{nM} \mathrm{HpH}$ trA wt for 180 min set as $100 \%$. 

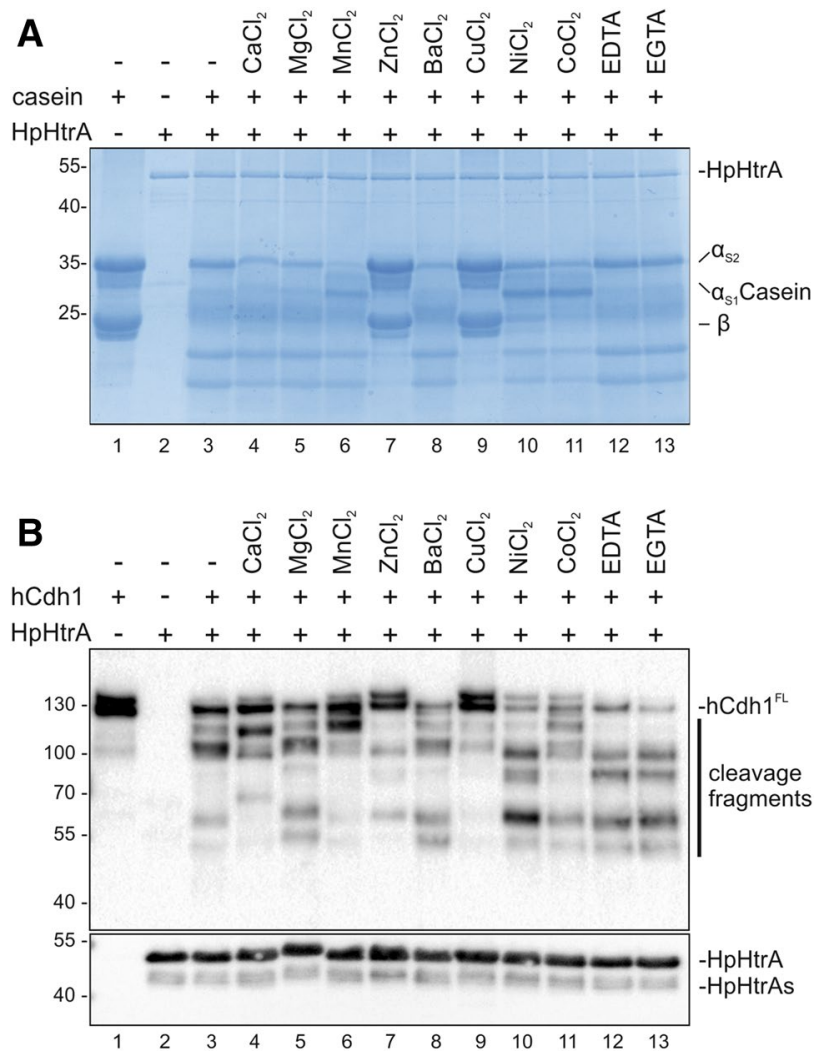

Figure 2. Divalent cations modulate the activity of $\mathrm{HpHtrA}$. (A) $10 \mu \mathrm{g}$ casein composed of $\alpha_{\mathrm{S}^{-}}, \alpha_{\mathrm{S}^{-}}$and $\beta$-casein were incubated with $250 \mathrm{ng} \mathrm{HpHtrA}$ for $16 \mathrm{~h}$ at $37^{\circ} \mathrm{C}$ in $50 \mathrm{mM}$ HEPES buffer ( $\mathrm{pH}$ 7.4). Where indicated, $1 \mathrm{mM}$ of the different divalent ions, EDTA, or EGTA was added. Proteins were separated by SDSPAGE and stained with Coomassie Brilliant Blue G250. (B) $50 \mathrm{ng}$ hCdh1 were incubated with $250 \mathrm{ng} \mathrm{HpHtrA}$ for $16 \mathrm{~h}$ at $37^{\circ} \mathrm{C}$ in $50 \mathrm{mM}$ HEPES buffer ( $\mathrm{pH}$ 7.4). Where indicated, $1 \mathrm{mM}$ of the different divalent ions, EDTA, or EGTA was added. Full length hCdh1 $\left(\mathrm{Cdh}^{\mathrm{FL}}, 125 \mathrm{kDa}\right)$ and hCdh1 cleavage fragments were detected by Western blot using an antibody recognizing the EC5 domain of hCdh1. HpHtrA and the auto-processed $\mathrm{HpHtrA}(\mathrm{HpHtrAs})$ were detected using a polyclonal HpHtrA antibody.

process $^{11,12}$, but has not yet been experimentally verified (Fig. 1A, right panel). Based on this refined cleavage site pattern, a FRET peptide consisting of the optimized sequence AQRVAF, the N-terminal fluorophore 2-aminobenzoyl (2-Abz) and the C-terminal quencher 3-nitro-tyrosine $\left.\mathrm{Y}_{\left(\mathrm{NO}_{2}\right.}\right)$ was synthesized (Fig. S2). This was equally well cleaved by trypsin and by HpHtrA with R and V, respectively, in position P1 (Fig. $1 \mathrm{~B}$ and Fig. S3 and S4). Intramolecular fluorescence quenching of the FRET peptide was highly efficient (Fig. S3) and cleavage using trypsin and HtrA wild type (wt) revealed a strong increase in emitted fluorescence, whereas the inactive mutant of HtrA (SA) did not affect the FRET substrate (Fig. 1C). Mass-spectrometry analyses demonstrated HtrA-specific cleavage with V in the P1 position (Fig. S4). The kinetics of the proteolytic activity of increasing $\mathrm{HpHtrA}$ wt concentrations demonstrated effective cleavage of the FRET peptide already at low concentrations compared to the inactive HtrA SA mutant (Fig. 1D).

The divalent cations $\mathrm{Zn}^{++}$and $\mathrm{Cu}^{++}$block HpHtrA-mediated E-cadherin cleavage. The FRET peptide assay is a suitable approach for drug screening to identify and optimize HpHtrA inhibitors. A wide range of non-metalloproteases can be inhibited by $\mathrm{Zn}^{++}$, including trypsin, kallikrein, and thrombin ${ }^{33,36,37}$. Following our observation that calcium ions efficiently prevent E-cadherin ectodomain shedding by covering the HpHtrAtargeted signature sites in the substrate ${ }^{11,12}$, we carried out a detailed investigation of the effects of divalent ions on $H$. pylori HtrA activity and substrate cleavage. In a first approach, recombinant HpHtrA was incubated with casein composed of $\alpha_{\mathrm{S}^{-}}, \alpha_{\mathrm{S}^{-}}$, and $\beta$-casein as a substrate and cleavage was analyzed in Coomassie-stained protein gels (Fig. 2A). HpHtrA efficiently degraded $\beta$-, $\alpha_{\mathrm{S} 1^{-}}$and, to a lesser extent, $\alpha_{\mathrm{S} 2}$-casein (Fig. 2A, lane 3). Among the metal ions tested, $\mathrm{Zn}^{++}$and $\mathrm{Cu}^{++}$strongly inhibited HtrA activity, indicating a direct effect of these divalent cations on the proteolytic activity of HpHtrA (Fig. 2A, lanes 7 and 9). The chelating agents EDTA and EGTA were added as controls, and these did not alter HtrA-mediated casein degradation (Fig. 2A, lanes 12 and 13). These data imply that divalent transition metals can differentially influence the activity of HpHtrA. Casein degradation by HtrA expressed by Borrelia burgdorferi (BbHtrA) is similarly inhibited by $\mathrm{Zn}^{++}$and $\mathrm{Cu}^{++}$, and has also been observed for DegP from E. coli and human HtrA ${ }^{38}$. Interestingly, the crystal structure of the HtrA homolog A (HhoA) from the photosynthetic cyanobacterium Synechocystis sp. PCC 6,803 revealed that the 
hexameric structure contains a $\mathrm{Zn}^{++}$ion within the central channel, which inactivates HhoA in a casein cleavage assay ${ }^{39}$. These data support our findings that $\mathrm{HpHtrA}$ can be inhibited through direct binding of $\mathrm{Zn}^{++}$and $\mathrm{Cu}^{++}$.

To determine whether this inhibition is caused through direct effects on the HtrA protease or through interference with the HtrA substrate casein, we further analyzed the effect of the metal ions on HtrA-mediated E-cadherin cleavage. Recombinant human E-cadherin (hCdh1) was incubated with recombinant HpHtrA for $16 \mathrm{~h}$ in the presence of various divalent cations as indicated. Fragments of hCdh1 were detected by Western blot analyses using an antibody recognizing the EC5 domain of E-cadherin. Efficient HpHtrA-mediated cleavage of hCdh1 was indicated by the presence of the characteristic HtrA-induced fragmentation pattern ${ }^{11}$ (Fig. 2B, lane 3). The addition of $\mathrm{Ca}^{++}$significantly blocked hCdh1 cleavage, while the chelating agents EDTA and EGTA considerably enhanced hCdh1 fragmentation compared to HpHtrA wt alone, as previously reported ${ }^{12}$ (Fig. 2B, lanes 4, 12 and 13). A drastic inhibitory effect was observed after the addition of $\mathrm{Zn}^{++}$and $\mathrm{Cu}^{++}$since HpHtrA-mediated hCdh1 fragmentation was strongly decreased (Fig. 2B, lanes 7 and 9). This is consistent with the in vitro cleavage experiments using casein as a substrate (Fig. 2A). These data suggest that $\mathrm{Zn}^{++}$and $\mathrm{Cu}^{++}$interfere with $\mathrm{HpHtrA}$ activity rather than bind to the substrate. This is obviously in contrast to $\mathrm{Ca}^{++}$, which binds to the $\mathrm{Ca}^{++}$-binding motifs positioned between the individual EC domains. Binding of $\mathrm{Ca}^{++}$is required for functional intermolecular interactions in cis and trans between the extracellular domains of E-cadherin on adjacent epithelial cells. In particular, these $\mathrm{Ca}^{++}$-binding motifs have been previously identified as cleavage sites for $\mathrm{HtrA}$. Hence, $\mathrm{Ca}^{++}$binding masks the motifs and prevents further fragmentation of the soluble $90 \mathrm{kDa}$ extracellular domain of E-cadherin upon infection with $H$. pylori ${ }^{11,12}$.

In order to further refine the inhibitory action of $\mathrm{Zn}^{++}$and $\mathrm{Cu}^{++}$, we performed titration experiments to determine the concentrations of $\mathrm{Zn}^{++}$and $\mathrm{Cu}^{++}$that are required for HtrA inhibition using the FRET peptide assay (Fig. 3A). Importantly, addition of $\mathrm{Zn}^{++}$and $\mathrm{Cu}^{++}$alone did not quench the fluorescent signal (Fig. S5), confirming the specificity of the measurement and the putative broad application of the FRET peptide for future drug screening. The relative fluorescence after $15 \mathrm{~min}$ and $180 \mathrm{~min}$ demonstrated that increasing concentrations of $\mathrm{Zn}^{++}$and $\mathrm{Cu}^{++}$significantly hampered HtrA activity (Fig. 3A). The half maximal inhibitory concentration $\left(\mathrm{IC}_{50}\right)$ values calculated for $\mathrm{Zn}^{++}$were $649.5 \mathrm{nM}$ (95\% confidence interval 560-746.1 nM) after $15 \mathrm{~min}$ and $2.57 \mu \mathrm{M}(95 \%$ confidence interval 2.382-2.774 $\mu \mathrm{M})$ after $180 \mathrm{~min}$. $\mathrm{Cu}^{++}$exhibited an $\mathrm{IC}_{50}$ of $295.4 \mathrm{nM}$ (95\% confidence interval $255.8-342.7 \mathrm{nM}$ ) after $15 \mathrm{~min}$ and of $937.5 \mathrm{nM}$ (95\% confidence interval 890.9-980.4 nM) after $180 \mathrm{~min}$, indicating efficient HpHtrA inactivation. The inhibition of HpHtrA wt detected in the FRET peptide assay was also compared with in vitro cleavage experiments using hCdh1 or casein as substrates. As a control, we included a proteolytically inactive $\mathrm{HpHtrA}$ mutant $(\mathrm{SA})^{4,40}$, which does not process hCdh1 or casein. $\mathrm{Zn}^{++}$ clearly inhibited HpHtrA-mediated hCdh1 fragmentation at a concentration of $50 \mu \mathrm{M}$ (Fig. 3B, lane 4) and higher $\mathrm{Zn}^{++}$concentrations blocked hCdh1 cleavage even more efficiently (Fig. 3B, lanes 5-8). In contrast to hCdh1 cleavage, the caseinolytic activity of $\mathrm{HpHtrA}$ was not affected by low $\mathrm{Zn}^{++}$or $\mathrm{Cu}^{++}$concentrations (Fig. 3C) suggesting that casein can absorb $\mathrm{Zn}^{++}$and $\mathrm{Cu}^{++}$as previously reported ${ }^{41}$ and hence interfere with cleavage activity. A slight inhibitory effect could be detected using $250 \mu \mathrm{M} \mathrm{Zn}^{++}$or $\mathrm{Cu}^{++}$, which was further enhanced at increasing concentrations (Fig. 3C, lanes 6-8). An increase up to 500-1,000 $\mu \mathrm{M}$ was required to fully inhibit casein cleavage (Fig. 3C, lanes 7-8). The different concentrations required for efficient HpHtrA inhibition detected in the FRET peptide assay and the in vitro cleavage experiment might be due to the increased accessibility of the FRET peptide, which contains a single, conformation-independent consensus cleavage site rather than folded complex proteins. Therefore, we conclude that using the FRET peptide as a substrate for HpHtrA is a highly sensitive and reliable approach to quantify HtrA activity.

The $\mathrm{IC}_{50}$ values of $\mathrm{Zn}^{++}$and $\mathrm{Cu}^{++}$inhibition are not within physiological concentrations (free plasma concentrations are $\sim 10^{-9} \mathrm{~mol} / \mathrm{l}$ for $\mathrm{Zn}^{++}$and $\sim 1.6 \times 10^{-11} \mathrm{~mol} / \mathrm{l}$ for $\left.\mathrm{Cu}^{++}\right)^{42}$. However, in combination with serine protease inhibitors, zinc has been reported to be a potent intensifier of moderate small molecule inhibitors ${ }^{33,37,43}$. Even though not all serine proteases contain typical $\mathrm{Zn}^{++}$-binding sites, which are characterized by two histidine residues with their imidazole side-chains as ligands for $\mathrm{Zn}^{++}$, it has been suggested that $\mathrm{Zn}^{++}$and $\mathrm{Cu}^{++}$bind in the active pockets of thrombin ${ }^{33}, \operatorname{trypsin}^{33}$, and kallikrein ${ }^{36}$ and bridge the inhibitor to the active site leading to an efficient inhibition. These studies demonstrated that lower concentrations of both, inhibitor and $\mathrm{Zn}^{++}$, were sufficient to strongly potentiate inhibitory effects. Since we found that $\mathrm{Zn}^{++}$blocks HpHtrA activity, it is tempting to speculate that moderate HtrA inhibitors combined with a low concentration of $\mathrm{Zn}^{++}$ions may synergistically function as highly potent zinc-mediated serine protease inhibitors.

$\mathrm{Zn}^{++}$and $\mathrm{Cu}^{++}$differentially interact with HpHtrA. Oligomerization is required for the activation of the E. coli HtrA homologue DegP, which is converted into proteolytically active oligomers upon substrate binding ${ }^{44}$. HtrA proteases harbor several domains that are crucially important for assembly and activity. DegP/ $\mathrm{HtrA}$ proteases contain an N-terminally located signal peptide (SP), followed by the protease domain, which is characterized by the catalytic triad histidine $(\mathrm{H})$, aspartic acid (D), and serine (S). The C-terminally located domains PDZ1 and PDZ2 are important for substrate recognition and oligomerization ${ }^{44}$. Several regulatory loops (e.g. LA, LD, and L1-L3 loops) have been investigated for E. coli DegP, which share sequence similarities with HpHtrA (Fig. 4A, Fig. S6A, and Fig. S6B). An 'orphan' allosteric pocket $\left(\mathrm{I}_{161}-\mathrm{S}_{169}\right)$ placed between the PDZ1 domain and the serine protease domain has been identified in the $2.6 \AA \mathrm{X}$-ray structure of HpHtrA that functions as an important protein-protein interface (Fig. 4B and Fig. S6B) ${ }^{45,46}$. This allosteric pocket contains the amino acid motif $S_{164}, D_{165}, S_{166}$, and $D_{168}$, which is not only required for the stability and activity of HtrA oligomers $^{45}$, but also for binding small molecule inhibitors that block HtrA activity ${ }^{46}$. Although typical $\mathrm{Zn}^{++}$- or $\mathrm{Cu}^{++}$-binding motifs characterized by histidine-rich regions are not present in this region, HpHtrA and, in particular, the allosteric loop may exhibit additional $\mathrm{Zn}^{++}$- and $\mathrm{Cu}^{++}$-binding sites composed of aspartic acid (D), glutamic acid (E), or cysteine (C), which can bind $\mathrm{Zn}^{++}$or $\mathrm{Cu}^{++}$equally well ${ }^{47}$. Therefore, we wanted to investi- 


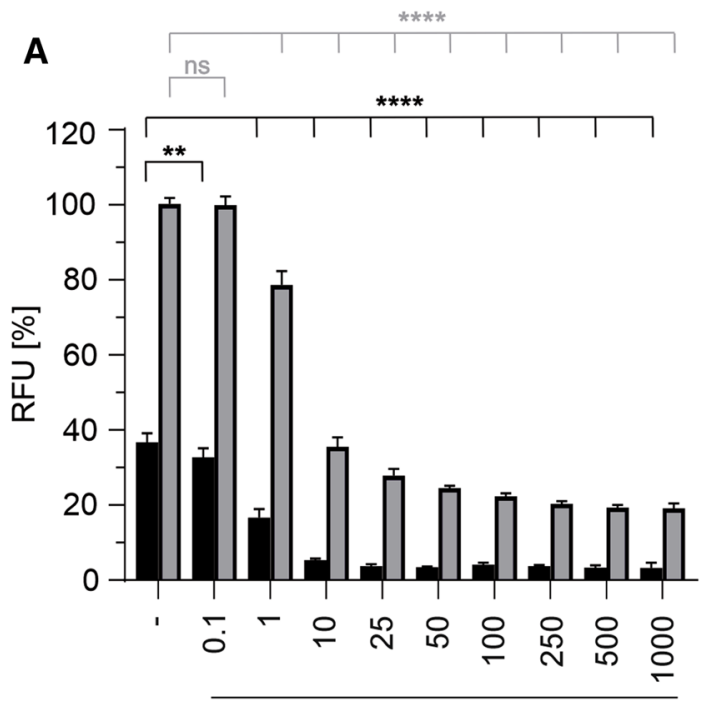

$\mathrm{ZnCl}_{2}[\mu \mathrm{M}]$
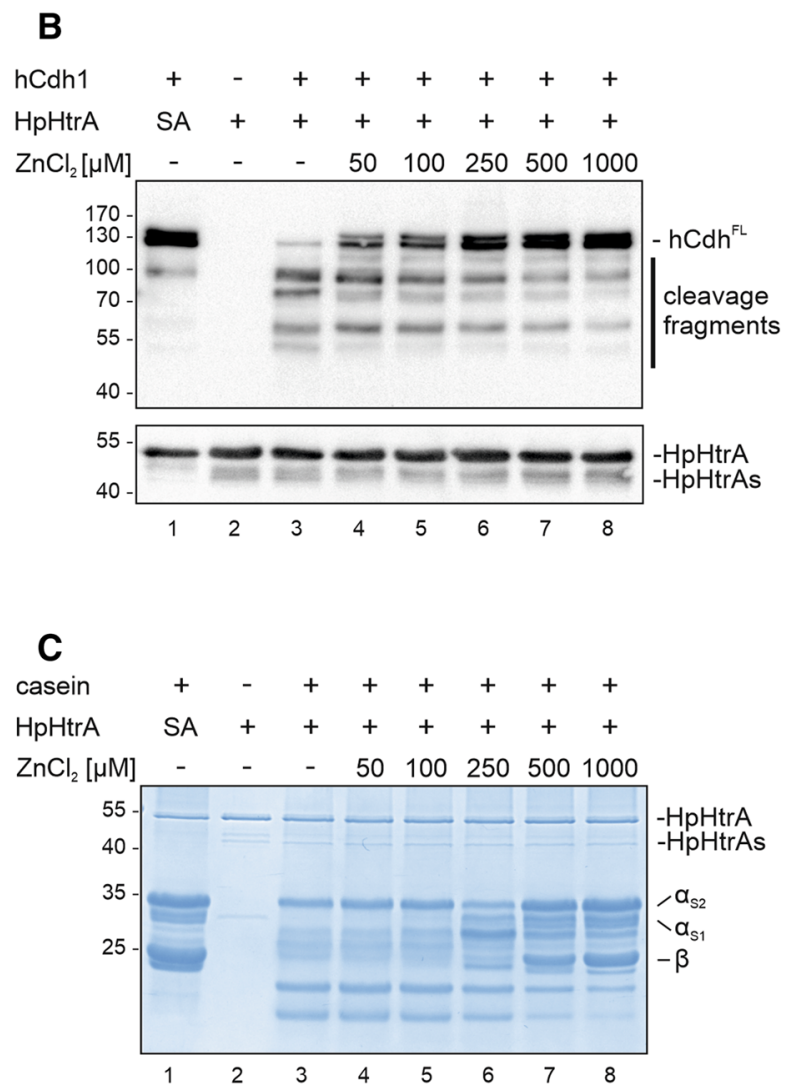

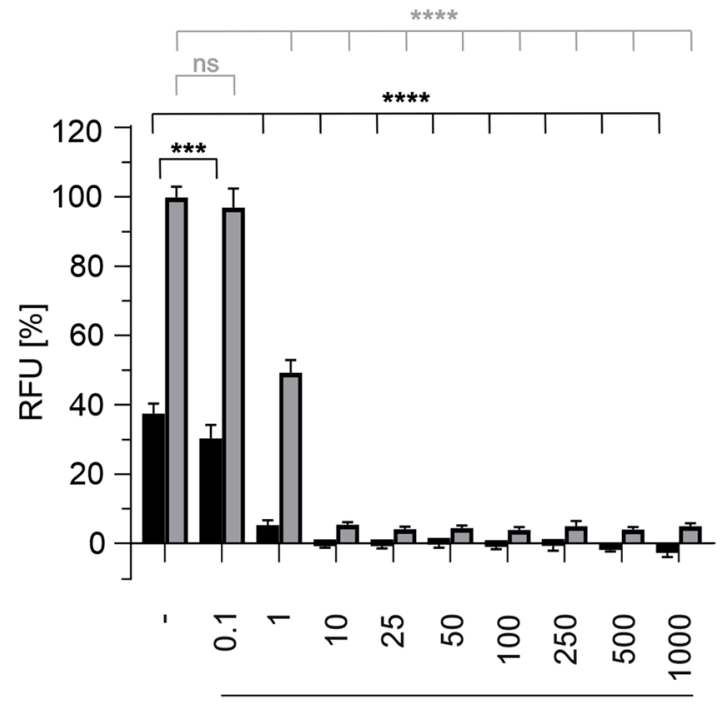

$\mathrm{CuCl}_{2}[\mu \mathrm{M}]$
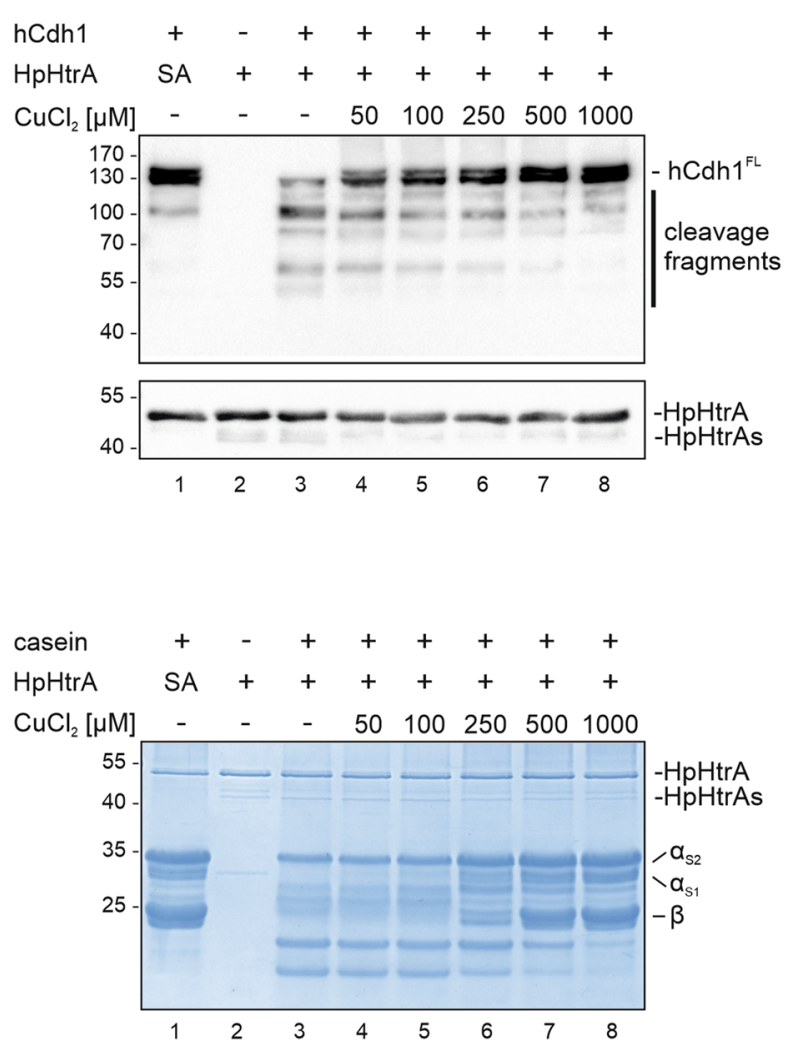

Figure 3. $\mathrm{ZnCl}_{2}$ and $\mathrm{CuCl}_{2}$ inhibit $\mathrm{HpHtrA}$ activity in a concentration-dependent manner. (A) $5 \mu \mathrm{M}$ FRET peptide were incubated with $250 \mathrm{nM} \mathrm{HpHtrA}$ and increasing concentrations of $\mathrm{ZnCl}_{2}$ (left panel) or $\mathrm{CuCl}_{2}$ (right panel) for $15 \mathrm{~min}$ (black bars) and $180 \mathrm{~min}$ (grey bars) at $37^{\circ} \mathrm{C}$ in $50 \mathrm{mM} \mathrm{HEPES} \mathrm{buffer} \mathrm{(pH} \mathrm{7.4).} \mathrm{The}$ data represent the relative fluorescence units $(R F U) \pm$ S.D. with fluorescent signals obtained from FRET peptide treated with $\mathrm{HpHtrA}$ wt set as $100 \%$. Asterisks indicate statistically significant differences $\left({ }^{* * * *} p<0.0001\right.$; ns, non-significant). (B) $50 \mathrm{ng} \mathrm{hCdh1}$ were incubated with $250 \mathrm{ng} \mathrm{HpHtrA}$ wt or inactive mutant (SA) and increasing concentrations of $\mathrm{ZnCl}_{2}$ (left panel) or $\mathrm{CuCl}_{2}$ (right panel) for $16 \mathrm{~h}$ at $37^{\circ} \mathrm{C}$ in $50 \mathrm{mM} \mathrm{HEPES}$ buffer ( $\mathrm{pH}$ 7.4). Full length hCdh1 (Cdh1 ${ }^{\mathrm{FL}}$ ) and cleavage fragments were detected by Western blot using an antibody recognizing the EC5 domain of hCdh1. HpHtrA and the auto-processed short HpHtrA (HpHtrAs) were detected using a polyclonal antibody. (C) $10 \mu \mathrm{g}$ casein composed of $\alpha_{\mathrm{S}^{-}}, \alpha_{\mathrm{S2}^{-}}$and $\beta$-casein were incubated with $250 \mathrm{ng} \mathrm{HpHtrA}$ wt or inactive mutant (SA) and with increasing concentrations of $\mathrm{ZnCl}_{2}$ (left panel) or $\mathrm{CuCl}_{2}$ (right panel). After incubation at $37^{\circ} \mathrm{C}$ for $16 \mathrm{~h}$ proteins were separated by SDS-PAGE and visualized by staining with Coomassie Brilliant Blue G250. 


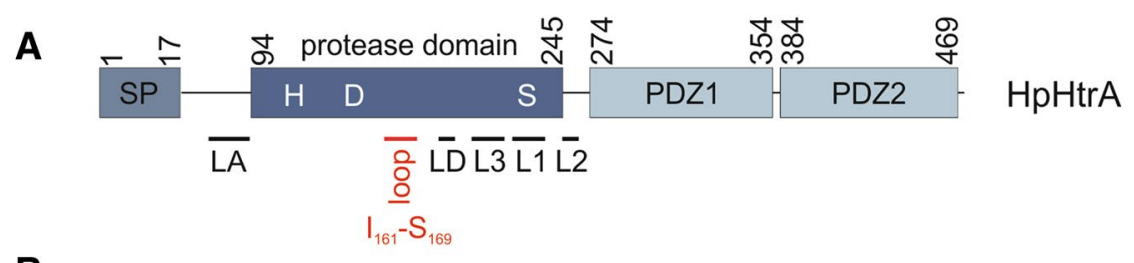

B
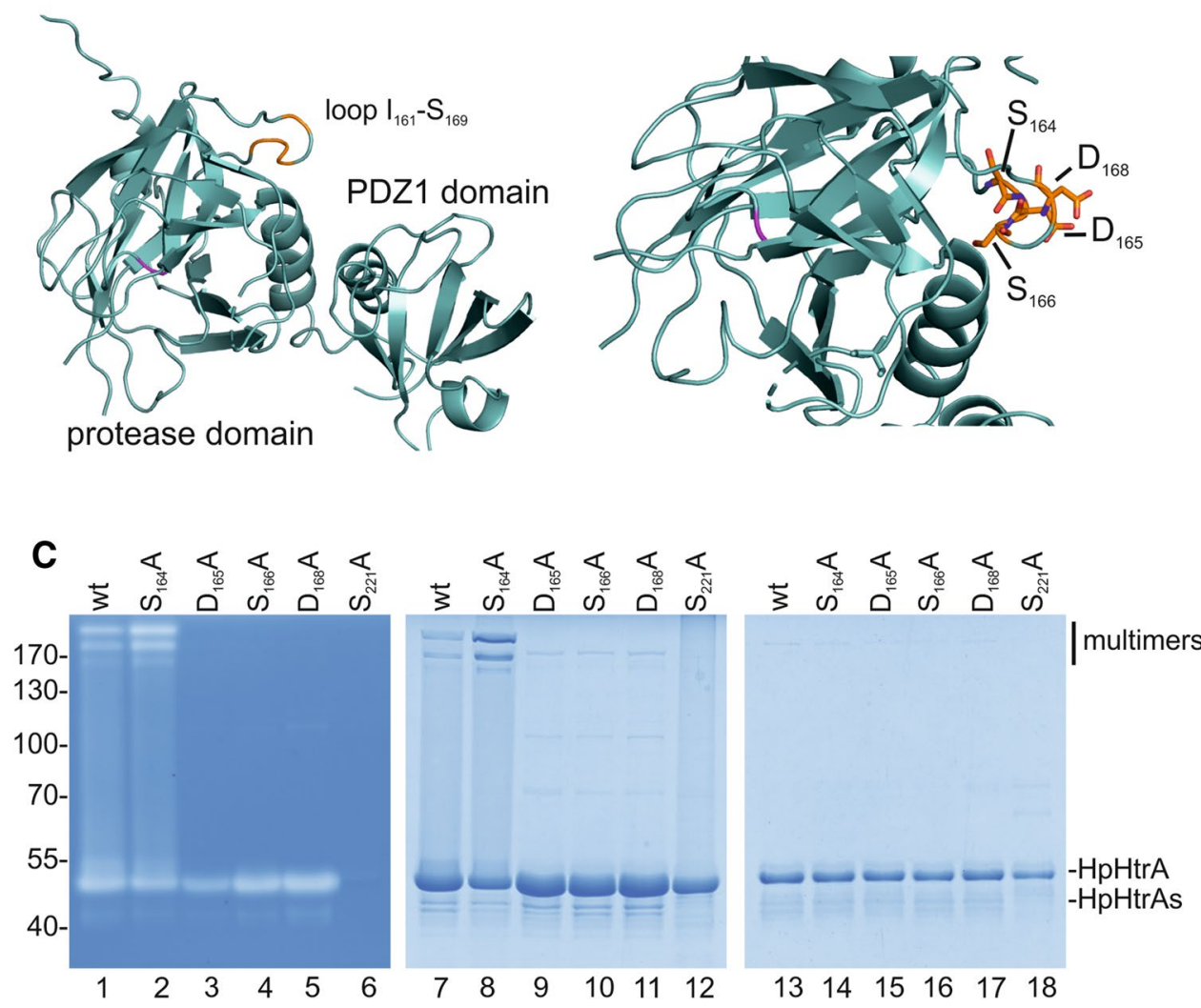

Figure 4. The allosteric ligand-binding loop is important for HtrA oligomer stabilization. (A) Model of HtrA showing the domain structure showing the signal peptide (SP), the extended linker region containing the LA loop, the protease domain with the catalytic triad histidine $(\mathrm{H})$, aspartic acid (D), and serine (S), and the PDZ1 and PDZ2 domains. The protease domain also contains the regulatory LD, L1, L2, and L3 loops. The position of the ligand-binding loop is highlighted in red. (B) X-ray structure of the protease domain of $\mathrm{HpHtrA}^{46}$ with $\mathrm{S}_{164}$, $\mathrm{D}_{165}, \mathrm{~S}_{166}$, and $\mathrm{D}_{168}$ indicated in the ligand-binding loop. $\mathrm{S}_{221}$ in the active center is highlighted in magenta. (C) Oligomerization and activity of HpHtrA wt, HpHtrA $S_{164} A, H p H t r A D_{165} A, H p H t r A S_{166} A, H p H t r A D_{168} A$, and $\mathrm{HpHtrA} \mathrm{S}_{221} \mathrm{~A}$ analyzed by casein zymography (lanes 1-6), non-reducing SDS-PAGE (lanes 7-12), and reducing SDS-PAGE (lanes 13-18).

gate whether $\mathrm{Zn}^{++}$and $\mathrm{Cu}^{++}$could target the aspartic acids exposed in this loop, which have previously been suggested as ligand-binding motifs ${ }^{47,48}$. The individual amino acids $S_{164}, D_{165}, S_{166}$, and $D_{168}$ were mutated to alanine and analyzed for oligomer stability (Fig. 4C). While HpHtrA $S_{164}$ A showed an increase in oligomer stability in casein zymography and SDS-PAGE under non-reducing conditions, oligomeric HpHtrA $\mathrm{D}_{165} \mathrm{~A}, \mathrm{HpH} \operatorname{Hr} \mathrm{S}_{166} \mathrm{~A}$, and $\mathrm{HpH} \operatorname{tr} \mathrm{A} \mathrm{D}_{168} \mathrm{~A}$ were completely disintegrated (Fig. 4C, left and middle panel), confirming that this loop has an important role in the allosteric regulation of HpHtrA. Proteolytically inactive HpHtrA $\mathrm{S}_{221} \mathrm{~A}$ was included as a negative control and purity of recombinant HpHtrA proteins was demonstrated in an SDS-PAGE under denaturing conditions (Fig. $4 \mathrm{C}$, right panel). Based on these data, we propose that $\mathrm{D}_{165}, \mathrm{~S}_{166}$, and $\mathrm{D}_{168}$ in $\mathrm{HpHtrA}$ are not required for proteolytic activity, but rather for stabilization of the active conformation. The proteolytic activity of HpHtrA mutants was then analyzed in in vitro cleavage experiments. Even though the stability of all three HpHtrA oligomers was clearly diminished, casein (Fig. 5A) and E-cadherin hydrolysis (Fig. 5B) were only slightly changed compared to HpHtrA wt. We assume that the limited HtrA activity is sufficient to cleave the substrates within $16 \mathrm{~h}$ of incubation. In addition, the kinetics of substrate hydrolysis by HtrA mutants was investigated using the FRET peptide assay. The quantification revealed that mutation of $\mathrm{S}_{164}$ or $\mathrm{S}_{166}$ led to a decrease in proteolytic activity of approximately $30 \%$. Mutation of $\mathrm{D}_{165}$ or $\mathrm{D}_{168}$ induced an even larger loss of HpHtrA activity (Fig. 5C), suggesting that mutations in the loop severely interfere with stability, oligomer formation, and/or activity. This observation is in agreement with our previous data, emphasizing the importance of this allosteric 

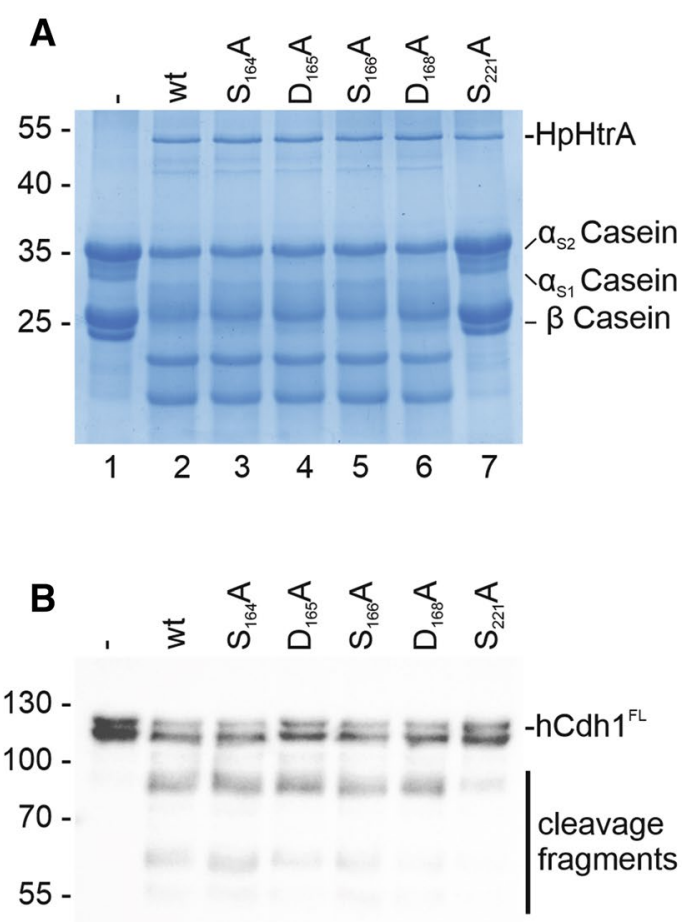

$40-$

55 -

$40-$

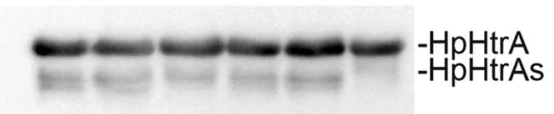

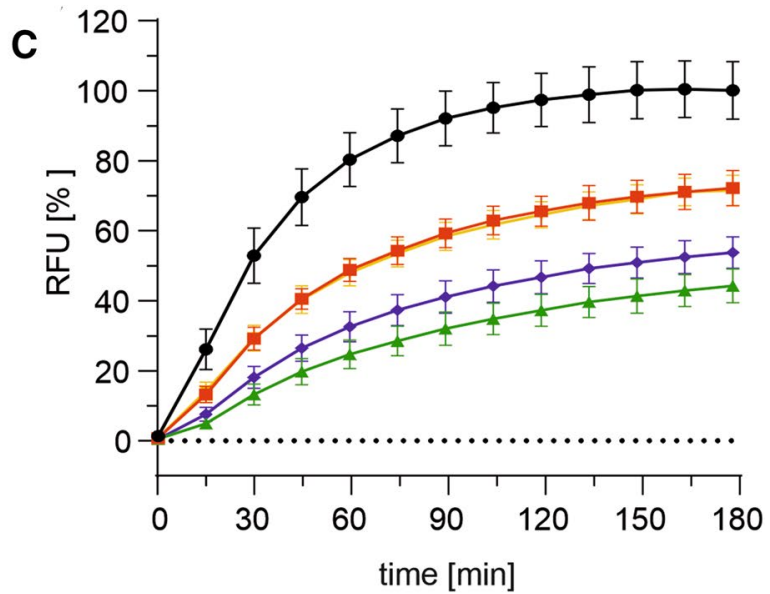

$\begin{array}{lllllll}1 & 2 & 3 & 4 & 5 & 6 & 7\end{array}$

Figure 5. Proteolytic activity of HpHtrA loop mutants. To analyze the proteolytic activity of HtrA wt and its

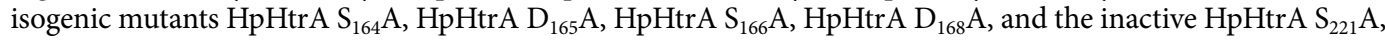
$10 \mu \mathrm{g}$ casein (A) or $50 \mathrm{ng}$ E-cadherin (hCdh1) (B) were incubated with $250 \mathrm{ng}$ HtrA variants as indicated for $16 \mathrm{~h}$ at $37^{\circ} \mathrm{C}$ in $50 \mathrm{mM}$ HEPES buffer ( $\mathrm{pH}$ 7.4). Cleavage of casein was analyzed by Coomassie-stained SDSPAGE and hCdh1 cleavage was determined by Western blot analysis using an antibody recognizing the EC5 domain of hCdh1. HpHtrA and the auto-processed HpHtrAs were detected as indicated. (C) The activity of the ligand-binding loop mutants was analyzed using the FRET peptide as a substrate. $5 \mu \mathrm{M}$ FRET peptide were incubated with $250 \mathrm{nM} \mathrm{HpHtrA}$ wt (black circle), HpHtrA $\mathrm{S}_{164} \mathrm{~A}$ (red square), HpHtrA $\mathrm{D}_{165} \mathrm{~A}$ (green triangle), $\mathrm{HpHtrA} \mathrm{S}_{166} \mathrm{~A}$ (yellow inverted triangles), and HpHtrA $\mathrm{D}_{168} \mathrm{~A}$ (blue rhombus) for $180 \mathrm{~min}$ at $37^{\circ} \mathrm{C}$ in $50 \mathrm{mM}$ HEPES buffer ( $\mathrm{pH}$ 7.4). The data represent the relative fluorescent units (RFU) \pm S.D. with fluorescent signals obtained from FRET peptide treated with HpHtrA wt for 180 min set as $100 \%$.

region. A bioactive ligand that was designed to bind to the allosteric pocket efficiently blocked the HtrA activity of $H$. pylori and Campylobacter jejuni and, subsequently, bacterial transmigration across the epithelial barrier ${ }^{46}$.

Since the allosteric loop is important for HpHtrA regulation and ligand binding, we further investigated whether $\mathrm{Zn}^{++}$and $\mathrm{Cu}^{++}$influence oligomerization of $\mathrm{HpHtrA}$ via this loop. HpHtrA proteins were treated with $\mathrm{Zn}^{++}$and $\mathrm{Cu}^{++}$and oligomerization was analyzed in Coomassie-stained protein gels under non-reducing conditions. In comparison to untreated HpHtrA wt, we observed a concentration-dependent effect of $\mathrm{Zn}^{++}$addition on HpHtrA oligomerization. A $\mathrm{Zn}^{++}$concentration of $50 \mu \mathrm{M}$ was sufficient to enhance oligomerization or the stability of HpHtrA (Fig. 6A, left panel, lane 2), suggesting direct binding of $\mathrm{Zn}^{++}$to HpHtrA. Using a thermal shift assay, we first determined the melting temperature of about $75^{\circ} \mathrm{C}$ for HpHtrA wt, which is quite high and indicates an enhanced stability that enables survival under stress conditions ${ }^{30,49}$. Mutation of $\mathrm{D}_{165}$ and $\mathrm{S}_{166}$ resulted in an increase in the thermal denaturation of HpHtrA, while $\mathrm{S}_{164}$ and $\mathrm{D}_{168}$ mutations did not alter stability (Fig. S7). HpHtrA mutants were then incubated with $\mathrm{Zn}^{++}$. HpHtrA wt was stabilized at a concentration of approximately $10 \mu \mathrm{M} \mathrm{Zn}^{++}$. A similar effect was shown for $\mathrm{HpHtrA} \mathrm{S}_{164} \mathrm{~A}$, indicating that $\mathrm{Zn}^{++}$does not interfere with $\mathrm{S}_{164}$. However, $\mathrm{Zn}^{++}$did not stabilize HpHtrA carrying mutations of $\mathrm{D}_{165}, \mathrm{~S}_{166}$, or $\mathrm{D}_{168}$ (Fig. $6 \mathrm{~A}$, right panel). This could be explained either by the observation that $H p H \operatorname{trA} D_{165} \mathrm{~A}, \mathrm{HpHtrA} \mathrm{S}_{166} \mathrm{~A}$, and HpHtrA $\mathrm{D}_{168} \mathrm{~A}$ mutants cannot form stable oligomers in general or by the assumption that $\mathrm{Zn}^{++}$does not directly bind to the allosteric loop, but rather into the active pocket of HpHtrA, as it has been suggested for other serine proteases ${ }^{33,36,37}$. To answer this question, the binding of $\mathrm{Zn}^{++}$was further analyzed by microscale thermophoresis (MST) (Table 1 and Fig. S8). Binding of $\mathrm{Zn}^{++}$could be detected for HpHtrA wt $\left(K_{d}=23 \mu \mathrm{M}\right)$ and HpHtrA $S_{164} \mathrm{~A}\left(K_{d}=55 \mu \mathrm{M}\right)$ with signal-to-noise ratios of 6.3 and 6.0, respectively. Although binding curves were also fitted for HpHtrA $\mathrm{D}_{165} \mathrm{~A}, \mathrm{~S}_{166} \mathrm{~A}$, and $\mathrm{D}_{168} \mathrm{~A}$ (Fig. S8), the signal-to-noise ratios were too low to prove binding of $\mathrm{Zn}^{++}$to the proteins 


\section{A}

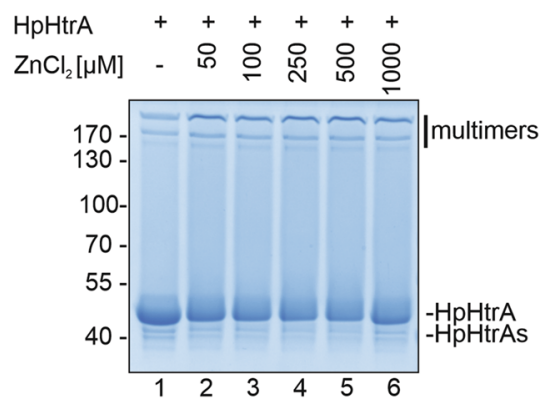

\section{B}
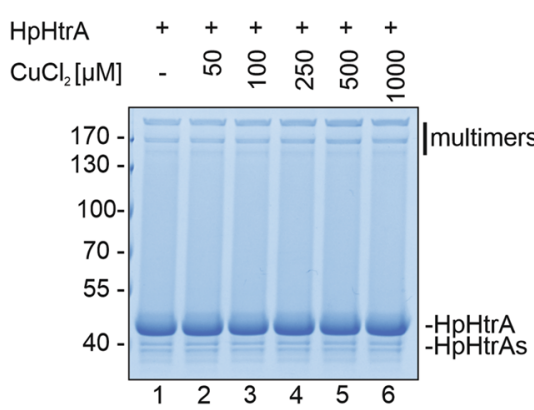
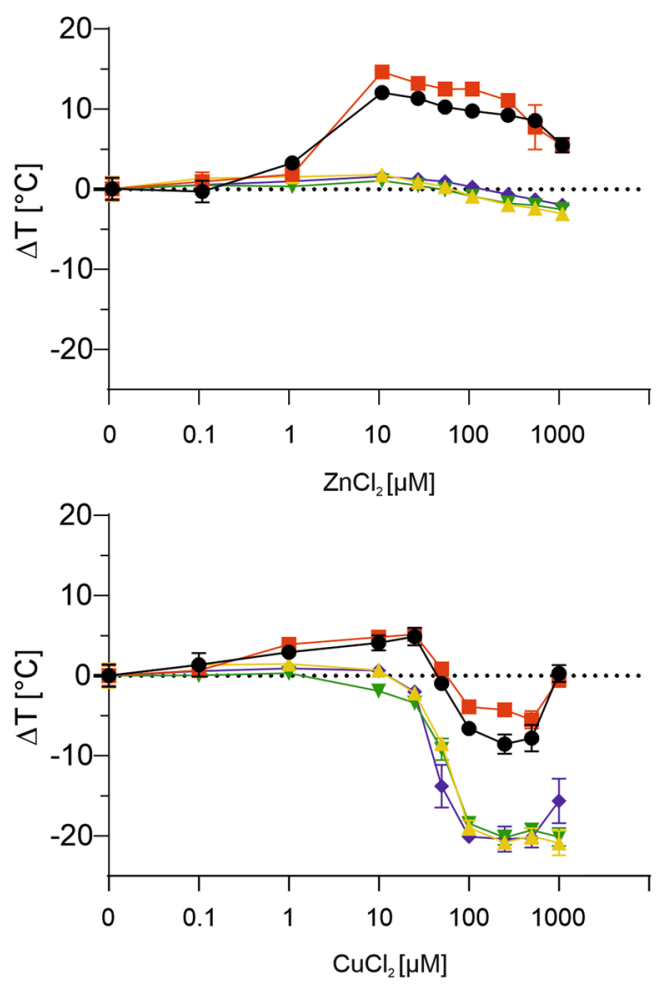

Figure 6. $\mathrm{Zn}^{++}$and $\mathrm{Cu}^{++}$ions interfere with the stability of $\mathrm{HpHtrA}$ via an allosteric loop. To investigate the effect of $\mathrm{ZnCl}_{2}$ and $\mathrm{CuCl}_{2}$ on the stability and activity of $\mathrm{HpHtrA}$ oligomers, HpHtrA wt was incubated with increasing concentrations of $\mathrm{ZnCl}_{2}(\mathbf{A})$ and $\mathrm{CuCl}_{2}(\mathbf{B})$ and then analyzed by a Coomassie-stained SDS-PAGE under non-reducing conditions (left panels). $4 \mu \mathrm{M}$ recombinant HpHtrA wt (black circles), $\mathrm{HpHtrA} \mathrm{S}_{164} \mathrm{~A}$

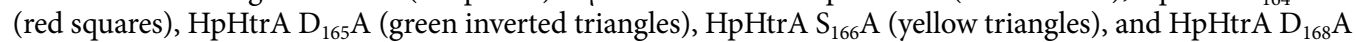
(blue rhombus) were incubated with SYPRO Orange and increasing concentrations of $\mathrm{ZnCl}_{2}$ and $\mathrm{CuCl}_{2}$ at a temperature ramp from $25-95^{\circ} \mathrm{C}$ (increase of $0.5^{\circ} \mathrm{C}$ per minute). Changes in melting temperature $\Delta \mathrm{T}_{\mathrm{m}}$ are presented normalized to the intrinsic $\mathrm{T}_{\mathrm{m}}$ of the individual HtrA mutant (right panels).

\begin{tabular}{|l|l|l|l|}
\hline Protein & Response amplitude & $\mathbf{S} \mathbf{N}^{\mathbf{a}}$ & $\boldsymbol{K}_{\boldsymbol{d}}^{\mathbf{b}}(\boldsymbol{\mu M} \pm \mathbf{S D})$ \\
\hline HpHtrA wt & 4.3 & 6.3 & $23 \pm 12$ \\
\hline HpHtrA S ${ }_{164} \mathrm{~A}$ & 3.6 & 6.0 & $55 \pm 34$ \\
\hline HpHtrA $\mathrm{D}_{165} \mathrm{~A}$ & 3.6 & 3.9 & n.d. $^{\mathrm{c}}$ \\
\hline HpHtrA S & & \\
\hline HpHtr $\mathrm{A} \mathrm{D}_{168} \mathrm{~A}$ & 3.9 & 3.8 & n.d \\
\hline
\end{tabular}

Table 1. HpHtrA interaction with $\mathrm{Zn}^{++}$. ${ }^{\mathrm{S}} \mathrm{S} / \mathrm{N}$, signal to noise ratio; ${ }^{\mathrm{b}} K_{d}$, dissociation constant; ${ }^{\mathrm{c} n}$.d., not determined.

(Table 1). $\mathrm{Cu}^{++}$was also investigated, but it strongly quenched the fluorescent signal at high concentrations and data analysis was therefore not possible (data not shown). Our results thus provide support for the hypothesis that $\mathrm{HpHtrA} \mathrm{D}_{165}$ and $\mathrm{D}_{168}$ are involved in the interaction with $\mathrm{Zn}^{++}$as a putative binding site. Since the mechanism of HpHtrA activity has not yet been intensively investigated, it is still unknown whether oligomerization is required for proteolytic activity or whether HpHtrA forms active oligomers in the zymogram after renaturation. But based on our data in this report, we conclude that the allosteric loop is important for the stability of oligomeric HpHtrA. Interaction with $\mathrm{Zn}^{++}$might drastically change the conformation of $\mathrm{HpHtrA}$, leading to an increase in oligomer stability, but also to an efficient inhibition of the proteolytic activity or substrate recognition. The detailed mechanism of HpHtrA oligomerization and activity will be further investigated in the future.

The data obtained from experiments with $\mathrm{Cu}^{++}$differ considerably from those obtained with $\mathrm{Zn}^{++}$. $\mathrm{HpHtrA}$ wt was only slightly stabilized at low $\mathrm{Cu}^{++}$concentrations, as analyzed by Coomassie-stained SDS-PAGE under non-reducing conditions (Fig. 6B, left panel). Comparing the HpHtrA mutants in the sensitive thermal shift assay, two modes of regulation were observed. At low concentrations, $\mathrm{Cu}^{++}$stabilized $\mathrm{HpHtrA}$ wt and $\mathrm{HpHtrA} \mathrm{S}{ }_{164} \mathrm{~A}$, but not the HpHtrA $D_{165} \mathrm{~A}, \mathrm{HpHtrA} \mathrm{S}_{166} \mathrm{~A}$, and HpHtrA $\mathrm{D}_{168} \mathrm{~A}$ mutants (Fig. 6B, right panel), resembling the effects 
detected in response to $\mathrm{Zn}^{++}$(Fig. 6A, right panel). Higher concentrations of $\mathrm{Cu}^{++}$finally destabilized $\mathrm{HpHtr} \mathrm{A}$ wt and HpHtrA $S_{164} A$. Interestingly, the HpHtrA $D_{165} A, H p H t r A S_{166} A$, and HpHtrA $D_{168} A$ mutants were more strongly destabilized by $\mathrm{Cu}^{++}$(Fig. $6 \mathrm{~B}$, right panel), indicating that these sites in $\mathrm{HpHtrA}$ are not only involved in oligomer stability, but also directly targeted by $\mathrm{Cu}^{++}$. In conclusion, we assume that $\mathrm{Cu}^{++}$has two binding motifs in the HpHtrA molecule. The first is the active site, which is a high affinity binding site for $\mathrm{Zn}^{++}$and $\mathrm{Cu}^{++}$and can bind the metals already at lower concentrations. This has been suggested for a number of serine proteases that bind $\mathrm{Zn}^{++}$and $\mathrm{Cu}^{++}$via the histidine in their pockets ${ }^{33,36,37}$. The second motif in the HpHtrA molecule is a low affinity binding site formed by the allosteric loop, the binding of which leads to a destabilization of HpHtrA. However, the detailed mechanism of $\mathrm{Zn}^{++}$and $\mathrm{Cu}^{++}$interference with $\mathrm{HpHtrA}$ needs further attention and will be investigated in future studies.

\section{Conclusion}

The significance of HtrA proteins in bacterial pathogenesis is well established. Therefore, potent inhibitors are desired to block $H$. pylori pathogenesis. First lead structures have been developed and successfully tested in in vitro systems ${ }^{28,29,46}$. In this study, we developed a sensitive FRET peptide assay for measurement of HpHtrA activity that is suitable for high-throughput screenings. As a paradigm for serine protease inhibition, we tested divalent ions as putative $\mathrm{HpHtrA}$ protease inhibitors and found $\mathrm{Zn}^{++}$and $\mathrm{Cu}^{++}$as inhibitory ligands. Although $\mathrm{HpHtrAs}$ do not require binding of metal ions for their regulation, $\mathrm{Zn}^{++}$ions have been described to block serine protease activity through binding to the active center ${ }^{33}$. Therefore, $\mathrm{Zn}^{++}$, and possibly $\mathrm{Cu}^{++}$, has the capacity to potentiate the inhibitory effects of moderate HtrA inhibitors, as it has previously been demonstrated for serine proteases. The development of a $\mathrm{Zn}^{++}$- and/or $\mathrm{Cu}^{++}$-mediated serine protease inhibitor functioning in a low nanomolar range is a stated objective in $H$. pylori research, since efficient inhibition of HpHtrA prevents bacterial pathogenesis and significantly attenuates $H$. pylori growth and survival.

\section{Methods}

Recombinant proteins. Recombinant human E-cadherin (hCdh1, D155-I707, accession no. NP_004351) was obtained from Sino Biological (Vienna, Austria). According to the manufacturer's protocol, the lyophilized hCdh1 was reconstituted in sterile water to give a concentration of $250 \mathrm{ng} / \mathrm{ml}$. Casein was obtained from Carl Roth (Karlsruhe, Germany) and reconstituted in water. Purification of HtrA wild type (wt) from the H. pylori strain Hp26695 (HpHtrA, G18-K475, UniProt G2J5T2), its isogenic inactive mutant (HpHtrA S 221 A), as well as HpHtrA mutants $\mathrm{S}_{164} \mathrm{~A}, \mathrm{D}_{165} \mathrm{~A}, \mathrm{~S}_{166} \mathrm{~A}$, and $\mathrm{D}_{168} \mathrm{~A}$ was performed as previously described ${ }^{40}$. Briefly, transformed E. coli BL21 were grown in terrific broth (TB) medium to an $\mathrm{OD}_{600}$ of 0.7 and expression of glutathione S-transferase (GST)-HtrA was induced by addition of $100 \mu \mathrm{M}$ isopropyl $\beta$-D-1-thiogalactopyranoside (IPTG) for $3 \mathrm{~h}$ at $30{ }^{\circ} \mathrm{C}$. The bacteria were pelleted and lysed by sonication in phosphate-buffered saline (PBS). The lysate was cleared by centrifugation and recombinant GST-tagged HpHtrA proteins were bound to glutathione sepharose beads (GE Healthcare Life Sciences, Vienna, Austria). The GST tag was removed by addition of PreScisssion protease (GE Healthcare Life Sciences, Vienna, Austria) for $16 \mathrm{~h}$ at $4{ }^{\circ} \mathrm{C}$. After purification, the proteins were dialyzed against $50 \mathrm{mM}$ tris(hydroxymethyl)aminomethane (Tris)/ $\mathrm{HCl}(\mathrm{pH} 7.5)$ and $150 \mathrm{mM} \mathrm{NaCl}$. Purity of proteins was routinely determined by sodium dodecyl sulfate polyacrylamide gel electrophoresis (SDS-PAGE) and staining with Coomassie Brilliant Blue G250 (Carl Roth, Karlsruhe, Germany).

DIPPS. Direct in-gel profiling of protease specificity (DIPPS) has been described previously ${ }^{35}$. Briefly, $150 \mu \mathrm{g}$ of the cellular proteome of MKN-28 cells was separated by SDS-PAGE and stained with Coomassie Brilliant Blue G250. Protein lanes were sliced, cut into pieces, and destained twice with $150 \mu \mathrm{l} 50 \%$ acetonitrile in $25 \mathrm{mM}$ ammonium bicarbonate for $30 \mathrm{~min}$ at $25^{\circ} \mathrm{C}$ and $1,200 \mathrm{rpm}$. The gel pieces were dehydrated with $100 \%$ acetonitrile and vacuum-dried. The dehydrated pieces were incubated with $1 \mu \mathrm{M} \mathrm{HpHtrA}$ in $100 \mathrm{mM}$ Tris (pH 8.0) and $50 \mathrm{mM} \mathrm{NaCl}$ for $2 \mathrm{~h}$ at $37^{\circ} \mathrm{C}$. Following in-gel proteolysis, the generated peptides were extracted from the gel and analyzed by LC-MS/MS using an Orbitrap LTQ Velos mass spectrometer coupled to EASY-nanoLC II HPLC unit (Thermo Fischer Scientific). Database searches were performed using the MaxQuant software package version 1.6.3.4 $4^{50,51}$ and UniProt derived human reference proteome (UniProtKB, Homo sapiens, canonical database containing 20,402 entries, released in February 2019), as described previously ${ }^{35}$. The cleaved peptides were identified with a length-limited unspecific database search and aligned to generate a substrate specificity profile of the studied protease. Visualization of relative ratios as iceLogos ${ }^{52}$ provided unambiguous insight into the extended cleavage preferences of HpHtrA.

FRET peptide assay. For the establishment of a FRET-based assay for the quantification of the HpHtrA activity, the 2-Abz/3-nitrotyrosine FRET pair ${ }^{53-55}$ was introduced into the sequence AQRVAF: the fluorophore (2-Abz, Ex/Em 320/435 nm) was coupled at the N-terminus, whereas the quencher (3-nitrotyrosine, Ex $425 \mathrm{~nm}^{56}$ ) was positioned at the C-end. The FRET activity of this peptide was first confirmed by measuring the fluorescence emission in the range $400-450 \mathrm{~nm}$ before and after the trypsin-mediated cleavage of the peptide bond R_V (Fig. S3). The measurements were performed in a black, flat-bottom 96-well plate (Nunc, Thermo Scientific, Schwerte, Germany) at $37^{\circ} \mathrm{C} .5 \mu \mathrm{M}$ of the peptide were incubated with $250 \mathrm{nM}$ HpHtrA and $125 \mathrm{nM}$ trypsin in $50 \mathrm{mM}$ HEPES buffer ( $\mathrm{pH}$ 7.4). Where indicated, increasing concentrations of $\mathrm{ZnCl}_{2}$ or $\mathrm{CuCl}_{2}$ were added. Cleavage of the peptide leads to increasing fluorescence, which was measured in a plate reader (Infinite 200 PRO, TECAN, Groedig, Austria) with a filter setting of $320 \mathrm{~nm} / 425 \mathrm{~nm}$ (Ex/Em). Statistical analysis was performed with GraphPad Prism software (Vers. 8.0.2). One-way ANOVA was used to statistically compare changes in fluorescence between samples treated with $\mathrm{HpHtrA}$ wt or HpHtrA $\mathrm{S}_{221} \mathrm{~A}$ with those treated with trypsin or with increasing concentrations of $\mathrm{ZnCl}_{2}$ or $\mathrm{CuCl}_{2}$, or the untreated control. Three independent experi- 
ments containing three technical replicates were analyzed for every sample. Significance is indicated as nonsignificant (ns) for $p>0.05,{ }^{*}$ for $p<0.05,{ }^{* *}$ for $p<0.01$, ${ }^{* * *}$ for $p<0.001$, and ${ }^{\star * * *}$ for $p<0.0001$.

In vitro cleavage experiments, SDS-PAGE, and Western blot. For in vitro cleavage experiments, $10 \mu \mathrm{g}$ casein were incubated with $250 \mathrm{ng} \mathrm{HpHtrA}$ wt (MW 50,000) or inactive mutant in $20 \mu \mathrm{l} 50 \mathrm{mM}$ HEPES buffer ( $\mathrm{pH}$ 7.4) for $16 \mathrm{~h}$ at $37^{\circ} \mathrm{C}$. Where indicated, $1 \mathrm{mM}$ of $\mathrm{CaCl}_{2}, \mathrm{MgCl}_{2}, \mathrm{MnCl}_{2}, \mathrm{ZnCl}_{2}, \mathrm{BaCl}_{2}, \mathrm{CuCl}_{2}$, $\mathrm{NiCl}_{2}, \mathrm{CoCl}_{2}$, ethylenediaminetetraacetic acid (EDTA), or ethylene glycol-bis( $\beta$-aminoethyl ether)- $N, N, N^{\prime}, N^{\prime}-$ tetraacetic acid (EGTA) were added to the cleavage reactions. The proteins were separated by SDS-PAGE and visualized by staining with Coomassie Brilliant Blue G250 (Lactan, Vienna, Austria). Alternatively, $50 \mathrm{ng}$ recombinant hCdh1 were incubated with $250 \mathrm{ng} \mathrm{HpHtrA}$ wt or inactive mutant for $16 \mathrm{~h}$ at $37^{\circ} \mathrm{C}$ in combination with different chlorides as indicated. Proteins were separated using SDS-PAGE and blotted onto a nitrocellulose membrane. Human Cdh1 was detected by an antibody recognizing the EC5 domain of hCdh1 (Abcam, Cambridge, UK) and a polyclonal serum was used to detect $\mathrm{HpHtrA}^{22}$. Independent experiments were repeated at least three times.

Casein zymography and non-reducing and reducing SDS-PAGE. HpHtrA wt was incubated with $1 \mathrm{mM}$ of $\mathrm{CaCl}_{2}, \mathrm{MgCl}_{2}, \mathrm{MnCl}_{2}, \mathrm{ZnCl}_{2}, \mathrm{BaCl}_{2}, \mathrm{CuCl}_{2}, \mathrm{NiCl}_{2}, \mathrm{CoCl}_{2}$, EDTA, or EGTA in $50 \mathrm{mM}$ HEPES buffer (pH 7.4) for 60 min on ice. Non-reducing sample buffer without $\beta$-mercaptoethanol was added and the samples were separated by SDS-PAGE containing $0.1 \%$ casein (Carl Roth, Karlsruhe, Germany) as a substrate. The gel was incubated for $60 \mathrm{~min}$ in renaturing buffer (2.5\% Triton X-100) and equilibrated for 30 min in developing buffer (50 mM Tris- $\mathrm{HCl}, \mathrm{pH} 7.4,200 \mathrm{mM} \mathrm{NaCl}, 5 \mathrm{mM} \mathrm{CaCl}_{2}$, and $0.02 \%$ Brij-35) at room temperature under gentle agitation. Afterwards, the gel was incubated for $24 \mathrm{~h}$ at $37{ }^{\circ} \mathrm{C}$ in developing buffer under gentle agitation. To visualize caseinolytic activity, the gel was stained in 0.5\% Coomassie Brilliant Blue R250 (Carl Roth, Karlsruhe, Germany). For detection of multimers by SDS-PAGE, HpHtrA was separated by SDS-PAGE under non-reducing conditions. Proteins were visualized by staining with Coomassie Brilliant Blue G250. Independent experiments were repeated at least four times.

Thermal shift assay. Thermal shift assays were performed to determine the melting temperatures of recombinant $\mathrm{HpHtrA}$ proteins (wt, $\left.\mathrm{S}_{164} \mathrm{~A}, \mathrm{D}_{165} \mathrm{~A}, \mathrm{~S}_{166} \mathrm{~A}, \mathrm{D}_{168} \mathrm{~A}\right)$ in the presence of increasing concentrations of $\mathrm{ZnCl}_{2}$ or $\mathrm{CuCl}_{2}$. A change in the melting temperature in the presence $\mathrm{ZnCl}_{2}$ or $\mathrm{CuCl}_{2}$ indicates stabilization or destabilization of the protein and is therefore evidence for binding of $\mathrm{Zn}^{++}$or $\mathrm{Cu}^{++}$to $\mathrm{HpHtrA}$. Recombinant HpHtrA proteins (wt, $\mathrm{S}_{164} \mathrm{~A}, \mathrm{D}_{165} \mathrm{~A}, \mathrm{~S}_{166} \mathrm{~A}, \mathrm{D}_{168} \mathrm{~A}$ ) in $50 \mathrm{mM}$ HEPES buffer ( $\mathrm{pH}$ 7.4) were mixed with SYPRO Orange (Sigma-Aldrich, Vienna, Austria) to final concentrations of $4 \mu \mathrm{M}$ HpHtrA and $7 \times$ SYPRO Orange in a 96-well PCR plate. Where indicated, increasing concentrations of $\mathrm{ZnCl}_{2}$ and $\mathrm{CuCl}_{2}$ were added. Fluorescence data was collected using an Applied Bioscience StepOne Plus PCR cycler (Thermo Fisher Scientific, Schwerte, Germany) during a temperature ramp from $25-95^{\circ} \mathrm{C}\left(0.5^{\circ} \mathrm{C}\right.$ per min) with a 4 min hold at $25^{\circ} \mathrm{C}$ and $95{ }^{\circ} \mathrm{C}$. SYPRO Orange binds to exposed hydrophobic regions within the denatured HpHtrA proteins, which increases the fluorescence of the dye $\mathrm{e}^{57,58}$. The fluorescence emission signal can then be used to determine the melting temperature of the protein, which is located at the infliction point of the fluorescence signal curve. The experiment was performed in triplicates.

\section{Data availability}

The datasets generated and analyzed during the current study are available from the authors on request.

Received: 21 December 2019; Accepted: 9 June 2020

Published online: 29 June 2020

\section{References}

1. Global Burden of Disease Cancer Collaboration. Global, regional, and national cancer incidence, mortality, years of life lost, years lived with disability, and disability-adjusted life-years for 32 cancer groups, 1990 to 2015: a systematic analysis for the global burden of disease study. JAMA Oncol. 3, 524-548. https://doi.org/10.1001/jamaoncol.2016.5688 (2017).

2. Peek, R. M. \& Crabtree, J. E. Helicobacter infection and gastric neoplasia. J. Pathol. 208, 233-248. https://doi.org/10.1002/path.1868 (2006).

3. Blaser, M. J. \& Atherton, J. C. Helicobacter pylori persistence: biology and disease. J. Clin. Investig. 113, 321-333. https://doi. org/10.1172/JCI200420925 (2004).

4. Hoy, B. et al. Helicobacter pylori HtrA is a new secreted virulence factor that cleaves E-cadherin to disrupt intercellular adhesion. EMBO Rep. 11, 798-804. https://doi.org/10.1038/embor.2010.114 (2010).

5. Niessen, C. M., Leckband, D. \& Yap, A. S. Tissue organization by cadherin adhesion molecules: dynamic molecular and cellular mechanisms of morphogenetic regulation. Physiol. Rev. 91, 691-731. https://doi.org/10.1152/physrev.00004.2010 (2011).

6. Shapiro, L. \& Weis, W. I. Structure and biochemistry of cadherins and catenins. Cold Spring Harbor Perspect. Biol. 1, a003053. https ://doi.org/10.1101/cshperspect.a003053 (2009).

7. Maretzky, T. et al. ADAM10 mediates E-cadherin shedding and regulates epithelial cell-cell adhesion, migration, and $\beta$-catenin translocation. Proc. Natl. Acad. Sci. U. S. A. 102, 9182-9187. https://doi.org/10.1073/pnas.0500918102 (2005).

8. Repetto, O., De Paoli, P., De Re, V., Canzonieri, V. \& Cannizzaro, R. Levels of soluble E-cadherin in breast, gastric, and colorectal cancers. Biomed. Res. Int. 2014, 408047. https://doi.org/10.1155/2014/408047 (2014).

9. Gofuku, J. et al. Characterization of soluble E-cadherin as a disease marker in gastric cancer patients. Br. J. Cancer 78, 1095-1101 (1998).

10. Katayama, M. et al. Soluble E-cadherin fragments increased in circulation of cancer patients. Br. J. Cancer 69, 580-585 (1994).

11. Schmidt, T. P. et al. Identification of E-cadherin signature motifs functioning as cleavage sites for Helicobacter pylori HtrA. Sci. Rep. 6, 23264. https://doi.org/10.1038/srep23264 (2016). 
12. Schmidt, T. P., Goetz, C., Huemer, M., Schneider, G. \& Wessler, S. Calcium binding protects E-cadherin from cleavage by Helicobacter pylori HtrA. Gut Pathogens 8, 29. https://doi.org/10.1186/s13099-016-0112-6 (2016).

13. Tegtmeyer, N. et al. Helicobacter pylori employs a unique basolateral type IV secretion mechanism for CagA delivery. Cell Host Microbe 22, 552-560.e555. https://doi.org/10.1016/j.chom.2017.09.005 (2017).

14. Frees, D., Brondsted, L. \& Ingmer, H. Bacterial proteases and virulence. Sub-cell. Biochem. 66, 161-192. https://doi.org/10.1007/97894-007-5940-4_7 (2013).

15. Ingmer, H. \& Brondsted, L. Proteases in bacterial pathogenesis. Res. Microbiol. 160, 704-710. https://doi.org/10.1016/j.resmi c.2009.08.017 (2009).

16. Purdy, G. E., Fisher, C. R. \& Payne, S. M. IcsA surface presentation in Shigella flexneri requires the periplasmic chaperones DegP, Skp, and SurA. J. Bacteriol. 189, 5566-5573. https://doi.org/10.1128/jb.00483-07 (2007).

17. Wu, X. et al. The chlamydial periplasmic stress response serine protease cHtrA is secreted into host cell cytosol. BMC Microbiol. 11, 87. https://doi.org/10.1186/1471-2180-11-87 (2011).

18. Patel, P., De Boer, L., Timms, P. \& Huston, W. M. Evidence of a conserved role for Chlamydia HtrA in the replication phase of the chlamydial developmental cycle. Microbes Infect. 16, 690-694. https://doi.org/10.1016/j.micinf.2014.07.003 (2014).

19. Hoy, B. et al. Distinct roles of secreted HtrA proteases from gram-negative pathogens in cleaving the junctional protein and tumor suppressor E-cadherin. J. Biol. Chem. 287, 10115-10120. https://doi.org/10.1074/jbc.C111.333419 (2012).

20. Boehm, M. et al. Rapid paracellular transmigration of Campylobacter jejuni across polarized epithelial cells without affecting TER: role of proteolytic-active HtrA cleaving E-cadherin but not fibronectin. Gut Pathog. 4, 3. https://doi.org/10.1186/1757-4749-4-3 (2012).

21. Elmi, A. et al. Campylobacter jejuni outer membrane vesicle-associated proteolytic activity promotes bacterial invasion by mediating cleavage of intestinal epithelial cell E-cadherin and occludin. Cell. Microbiol. 18, 561-572. https://doi.org/10.1111/cmi.12534 (2016).

22. Abfalter, C. M. et al. HtrA-mediated E-cadherin cleavage is limited to DegP and DegQ homologs expressed by gram-negative pathogens. Cell Commun. Signal. 14, 30. https://doi.org/10.1186/s12964-016-0153-y (2016).

23. Waller, P. R. \& Sauer, R. T. Characterization of degQ and degS, Escherichia coli genes encoding homologs of the DegP protease. J. Bacteriol. 178, 1146-1153 (1996).

24. Kim, D.-Y. \& Kim, K.-K. Structure and function of HtrA family proteins, the key players in protein quality control. J. Biochem. Mol. Biol. 38, 266-274. https://doi.org/10.5483/BMBRep.2005.38.3.266 (2005).

25. Jiang, J. et al. Activation of DegP chaperone-protease via formation of large cage-like oligomers upon binding to substrate proteins. Proc. Natl. Acad. Sci. U. S. A. 105, 11939-11944. https://doi.org/10.1073/pnas.0805464105 (2008).

26. Shen, Q.-T. et al. Bowl-shaped oligomeric structures on membranes as DegP's new functional forms in protein quality control. Proc. Natl. Acad. Sci. U. S. A. 106, 4858-4863. https://doi.org/10.1073/pnas.0811780106 (2009).

27. Kim, S., Grant, R. A. \& Sauer, R. T. Covalent linkage of distinct substrate degrons controls assembly and disassembly of DegP proteolytic cages. Cell 145, 67-78. https://doi.org/10.1016/j.cell.2011.02.024 (2011).

28. Lower, M. et al. Inhibitors of Helicobacter pylori protease HtrA found by "virtual ligand" screening combat bacterial invasion of epithelia. PLoS ONE 6, e17986. https://doi.org/10.1371/journal.pone.0017986 (2011).

29. Perna, A. M. et al. Fragment-based de novo design reveals a small-molecule inhibitor of Helicobacter pylori HtrA. Angew. Chem. 54, 10244-10248. https://doi.org/10.1002/anie.201504035 (2015).

30. Zarzecka, U., Harrer, A., Zawilak-Pawlik, A., Skorko-Glonek, J. \& Backert, S. Chaperone activity of serine protease HtrA of Helicobacter pylori as a crucial survival factor under stress conditions. Cell Commun. Signal. 17, 161. https://doi.org/10.1186/s1296 4-019-0481-9 (2019).

31. Tegtmeyer, N. et al. Characterisation of worldwide Helicobacter pylori strains reveals genetic conservation and essentiality of serine protease HtrA. Mol. Microbiol. 99, 925-944. https://doi.org/10.1111/mmi.13276 (2016).

32. Zawilak-Pawlik, A. et al. Establishment of serine protease htrA mutants in Helicobacter pylori is associated with secA mutations. Sci. Rep. 9, 11794. https://doi.org/10.1038/s41598-019-48030-6 (2019).

33. Katz, B. A. et al. Design of potent selective zinc-mediated serine protease inhibitors. Nature 391, 608-612. https://doi. org/10.1038/35422 (1998)

34. Lower, M. et al. Prediction of extracellular proteases of the human pathogen Helicobacter pylori reveals proteolytic activity of the Hp1018/19 protein HtrA. PLoS ONE 3, e3510. https://doi.org/10.1371/journal.pone.0003510 (2008).

35. Vidmar, R., Vizovisek, M., Turk, D., Turk, B. \& Fonovic, M. Protease cleavage site fingerprinting by label-free in-gel degradomics reveals pH-dependent specificity switch of legumain. Embo J. 36, 2455-2465. https://doi.org/10.15252/embj.201796750 (2017).

36. Debela, M. et al. Chymotryptic specificity determinants in the $1.0 \mathrm{~A}$ structure of the zinc-inhibited human tissue kallikrein 7. Proc. Natl. Acad. Sci. U. S. A. 104, 16086-16091. https://doi.org/10.1073/pnas.0707811104 (2007).

37. Katz, B. A. \& Luong, C. Recruiting $\mathrm{Zn}^{2+}$ to mediate potent, specific inhibition of serine proteases. J. Mol. Biol. 292, 669-684. https ://doi.org/10.1006/jmbi.1999.3071 (1999).

38. Russell, T. M., Tang, X., Goldstein, J. M., Bagarozzi, D. \& Johnson, B. J. B. The salt-sensitive structure and zinc inhibition of Borrelia burgdorferi protease BbHtrA. Mol. Microbiol. 99, 586-596. https://doi.org/10.1111/mmi.13251 (2016).

39. Dong, W., Wang, J., Niu, G., Zhao, S. \& Liu, L. Crystal structure of the zinc-bound HhoA protease from Synechocystis sp. PCC 6803. FEBS Lett. 590, 3435-3442. https://doi.org/10.1002/1873-3468.12416 (2016).

40. Löwer, M. et al. Prediction of extracellular proteases of the human pathogen Helicobacter pylori reveals proteolytic activity of the Hp1018/19 protein HtrA. PLoS ONE 3, e3510. https://doi.org/10.1371/journal.pone.0003510 (2008).

41. Hansen, M., Sandstrom, B. \& Lonnerdal, B. The effect of casein phosphopeptides on zinc and calcium absorption from high phytate infant diets assessed in rat pups and Caco-2 cells. Pediatr. Res. 40, 547-552. https://doi.org/10.1203/00006450-199610000-00006 (1996).

42. Djurdjevic, P., Jakovljevic, I., Joksovic, L., Ivanovic, N. \& Jelikic-Stankov, M. The effect of some fluoroquinolone family members on biospeciation of copper(II), nickel(II) and zinc(II) ions in human plasma. Molecules 19, 12194-12223. https://doi.org/10.3390/ molecules190812194 (2014).

43. Janc, J. W. et al. A novel approach to serine protease inhibition: kinetic characterization of inhibitors whose potencies and selectivities are dramatically enhanced by zinc(II). Biochemistry 39, 4792-4800. https://doi.org/10.1021/bi992182j (2000).

44. Krojer, T. et al. Structural basis for the regulated protease and chaperone function of DegP. Nature 453, 885-890. https://doi. org/10.1038/nature07004 (2008).

45. Geppert, T., Hoy, B., Wessler, S. \& Schneider, G. Context-based identification of protein-protein interfaces and "hot-spot" residues. Chem. Biol. 18, 344-353. https://doi.org/10.1016/j.chembiol.2011.01.005 (2011).

46. Perna, A. M. et al. Inhibiting Helicobacter pylori HtrA protease by addressing a computationally predicted allosteric ligand binding site. Chem. Sci. 5, 3583-3590. https://doi.org/10.1039/c4sc01443j (2014).

47. Sharma, A., Sharma, D. \& Verma, S. K. In silico study of iron, zinc and copper binding proteins of Pseudomonas syringae pv. lapsa: emphasis on secreted metalloproteins. Front. Microbiol. 9, 1838. https://doi.org/10.3389/fmicb.2018.01838 (2018).

48. Kozlowski, H., Potocki, S., Remelli, M., Rowinska-Zyrek, M. \& Valensin, D. Specific metal ion binding sites in unstructured regions of proteins. Coord. Chem. Rev. 257, 2625-2638. https://doi.org/10.1016/j.ccr.2013.01.024 (2013).

49. Hoy, B., Brandstetter, H. \& Wessler, S. The stability and activity of recombinant Helicobacter pylori HtrA under stress conditions. J. Basic Microbiol. 53, 402-409. https://doi.org/10.1002/jobm.201200074 (2013). 
50. Cox, J. \& Mann, M. MaxQuant enables high peptide identification rates, individualized p.p.b.-range mass accuracies and proteomewide protein quantification. Nat. Biotechnol. 26, 1367-1372. https://doi.org/10.1038/nbt.1511 (2008).

51. Cox, J. et al. Andromeda: a peptide search engine integrated into the MaxQuant environment. J. Proteome Res. 10, $1794-1805$. https://doi.org/10.1021/pr101065j (2011).

52. Colaert, N., Helsens, K., Martens, L., Vandekerckhove, J. \& Gevaert, K. Improved visualization of protein consensus sequences by iceLogo. Nat. Methods 6, 786-787. https://doi.org/10.1038/nmeth1109-786 (2009).

53. Meldal, M. \& Breddam, K. Anthranilamide and nitrotyrosine as a donor-acceptor pair in internally quenched fluorescent substrates for endopeptidases: multicolumn peptide synthesis of enzyme substrates for subtilisin Carlsberg and pepsin. Anal. Biochem. 195, 141-147. https://doi.org/10.1016/0003-2697(91)90309-h (1991).

54. Bech, L. M., Sorensen, S. B. \& Breddam, K. Significance of hydrophobic S4-P4 interactions in subtilisin 309 from Bacillus lentus. Biochemistry 32, 2845-2852. https://doi.org/10.1021/bi00062a016 (1993).

55. Meldal, M., Svendsen, I., Breddam, K. \& Auzanneau, F. I. Portion-mixing peptide libraries of quenched fluorogenic substrates for complete subsite mapping of endoprotease specificity. Proc. Natl. Acad. Sci. U. S. A. 91, 3314-3318. https://doi.org/10.1073/ pnas.91.8.3314 (1994).

56. Riordan, J. F., Sokolovsky, M. \& Vallee, B. L. Environmentally sensitive tyrosyl residues. Nitration with tetranitromethane. Biochemistry 6, 358-361. https://doi.org/10.1021/bi00853a053 (1967).

57. Pantoliano, M. W. et al. High-density miniaturized thermal shift assays as a general strategy for drug discovery. J. Biomol. Screen. 6, 429-440. https://doi.org/10.1177/108705710100600609 (2001).

58. Lo, M. C. et al. Evaluation of fluorescence-based thermal shift assays for hit identification in drug discovery. Anal. Biochem. 332, 153-159. https://doi.org/10.1016/j.ab.2004.04.031 (2004).

\section{Acknowledgements}

The work of SW was supported by the Grants P_31507 and I_4360 from the Austrian Science Fund (FWF). The work was also supported by the grants from Slovene Research Agency (P1-0140 and N1-0126) to BT. We are grateful to Hans Brandstetter for critical discussions.

\section{Author contributions}

S.B., C.B., M.J., and G.C. performed zymography, Western blot experiments, thermal shift, MST and HtrA FRET peptide assays. M.V., M.F., and B.T. performed DIPPS analysis. C.C., F.G., and V.S. developed the FRET peptide assay. P.S., S.M.F., and C.B. prepared the HtrA models. G.O., G.P., G.S., and S.W. conceived the experiments. S.B. and S.W. wrote the manuscript.

\section{Competing interests}

The authors declare no competing interests.

\section{Additional information}

Supplementary information is available for this paper at https://doi.org/10.1038/s41598-020-67578-2.

Correspondence and requests for materials should be addressed to S.W.

Reprints and permissions information is available at www.nature.com/reprints.

Publisher's note Springer Nature remains neutral with regard to jurisdictional claims in published maps and institutional affiliations.

(c) (1) Open Access This article is licensed under a Creative Commons Attribution 4.0 International License, which permits use, sharing, adaptation, distribution and reproduction in any medium or format, as long as you give appropriate credit to the original author(s) and the source, provide a link to the Creative Commons license, and indicate if changes were made. The images or other third party material in this article are included in the article's Creative Commons license, unless indicated otherwise in a credit line to the material. If material is not included in the article's Creative Commons license and your intended use is not permitted by statutory regulation or exceeds the permitted use, you will need to obtain permission directly from the copyright holder. To view a copy of this license, visit http://creativecommons.org/licenses/by/4.0/.

(c) The Author(s) 2020 